\title{
Treating "Asthma" With A Scalpel: Achalasia Mimicking Asthma
}

Nittner-Marszalska M, Kopeć A, Jędrzejewska J, Pawłowicz R Department of Internal Medicine and Allergology, Wroclaw Medical University, Wroclaw, Poland

J Investig Allergol Clin Immunol 2019; Vol. 29(5): 394-396 doi: 10.18176/jiaci.0417

Key words: Asthma. Diffuse aspiration bronchiolitis. Achalasia.

Palabras clave: Asma. Bronquiolisis difusa por aspiración. Acalasia.

When asthma remains partially controlled or even uncontrolled despite qualified treatment, experts stress the need to verify the diagnosis and rule out conditions that can mimic asthma [1,2]. According to some reports, misdiagnosis of nonasthmatic conditions treated as uncontrolled asthma is as frequent as $12 \%-30 \%$; hence, a certain degree of skepticism is recommended [3].

An 18-year-old woman was referred to our Allergy Department with a diagnosis of severe asthma. Her asthma was partially controlled and sometimes uncontrolled, with signs of bronchial obstruction that persisted despite intensive treatment (GINA guidelines, step 5: daily doses of fluticasone propionate $1000 \mu \mathrm{g}$ and salmeterol $100 \mu \mathrm{g}$, with prednisone $20-40 \mathrm{mg} / \mathrm{d}$ for 5-7 d every second or third month). Since the onset of her disease (age 13 years), the main symptoms were cough, breathlessness, and wheezing that occurred predominantly at night, causing frequent nocturnal awakening. She also reported rhinorrhea during sleep. The patient's mother described the nocturnal symptoms as "noisy breathing". During the last 2 years, the patient had pneumonia twice, and several episodes of "bronchitis" treated with antibiotics. The patient denied having experienced paroxysmal dyspnea, exercise-triggered dyspnea, or dyspnea induced by other factors (specific or nonspecific). Similarly, she did not report any other symptoms, particularly gastric symptoms. She was sensitized to house dust mite, but had no family history of atopy or asthma and had never smoked cigarettes.

Physical examination and laboratory test results during hospitalization revealed no abnormalities. Spirometry confirmed a moderate obstructive picture $\left(\mathrm{FEV}_{1}, 1.92 \mathrm{~L}\right.$ [59.7\%]; FVC, 3.61 L [98.2\%]; $\left.\mathrm{FEV}_{1} / \mathrm{FVC}, 53.2 \%\right)$. Postbronchodilator spirometry revealed lack of response to inhaled bronchodilators. Body plethysmography showed elevated airway resistance, both inspiratory and expiratory (respectively $305 \%$ and $300 \%$ of predicted) and increased residual volume (254\%). Blood gasometry and FeNO (7 ppb) were normal. Neither sputum eosinophilia nor nasal discharge were recorded. The blood eosinophil count was normal. Chest radiograph findings were unremarkable. The chest $\mathrm{CT}$ scan revealed a massively dilated esophagus filled with food residue and, consequently, tracheal compression (Figure). It also revealed parenchymal lung changes in the form of distal diffuse 


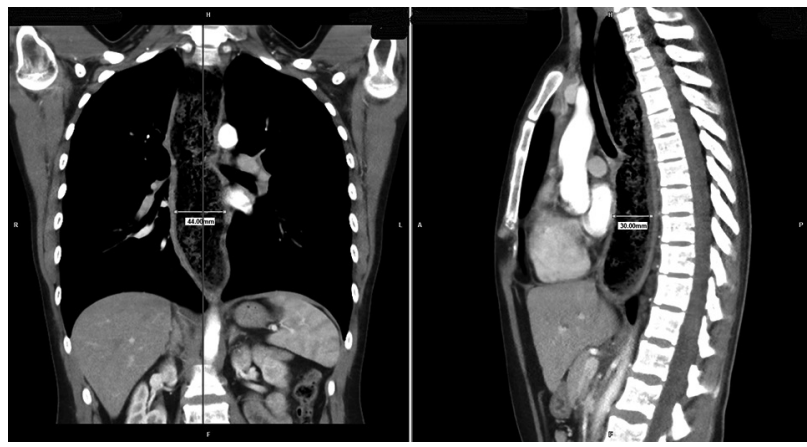

Figure. Computed tomography scan showing massive dilatation of the esophagus and tracheal compression.

consolidation, areas of ground-glass opacity, micronodules, and tree-in-bud opacities. Esophagogastroscopy showed a dilated esophagus. Esophageal high-resolution manometry revealed a hypertensive lower esophageal sphincter that did not relax on swallowing; similarly, there was no peristaltic wave in the esophagus. The patient was diagnosed with achalasia.

When the test results had been collected and the medical history was being completed, the patient reported that for at least 3 years, she had experienced nocturnal vomiting containing undigested food; her nasal discharge had also contained food particles. The symptoms were associated with persistent cough.

Once the diagnosis of achalasia was confirmed, the patient was referred for surgery (peroral endoscopic myotomy). A check-up 2 months after surgery revealed that cough, dyspnea, rhinorrhea, and nocturnal vomiting had considerably abated. All asthmatic medications were discontinued. Spirometry results returned to normal values $\left(\mathrm{FEV}_{1}, 3.89 \mathrm{~L}[121 \%]\right.$; FVC, $\left.4.3 \mathrm{~L}[117 \%] ; \mathrm{FEV}_{1} / \mathrm{FVC}, 90 \%\right)$. The result of the methacholine challenge test performed at that time was negative.

The present case concerns a patient with respiratory symptoms resulting from achalasia that were misdiagnosed as severe asthma. In fact, the symptoms reported were caused by recurrent aspiration of small amounts of gastric content that occurred largely at night over a period of a few years. The chest CT scans performed on admission to the Allergy Department were characteristic of bronchiolitis and reflected chronic bronchiolocentric inflammation caused by recurrent aspiration. The clinical picture and imaging scans pointed to a diagnosis of diffuse aspiration bronchiolitis (DAB) complicated by incidents of aspiration pneumonia. The term diffuse aspiration bronchiolitis was first used by Matsuse et al [4] as a name for a chronic inflammation of the bronchioles produced by frequent aspiration of foreign particles. Although DAB is usually diagnosed in the elderly, it has been reported in younger patients, with clinical manifestations similar to those found in the elderly [5-8]. In younger patients, the major risk factors responsible for $\mathrm{DAB}$ are dysphagia due to achalasia and gastroesophageal reflux disease with concomitant recurrent aspiration.

In the case we report, the diagnostic delay may have been caused by various factors. First, apart from a 5-year history of vomiting that was erroneously interpreted as a consequence rather than the cause of coughing, there were no accompanying symptoms characteristic of achalasia. Second, auscultatory phenomena were interpreted as asthmatic wheezing, while they might in fact have resulted from pressure on the trachea and/or bronchiolitis, which can also be responsible for variations in airflow obstruction in spirometry. Third, achalasia is a rare disorder, diagnosed mostly in elderly adults (generally during the sixth decade of life, with an estimated prevalence and incidence, respectively, of 10.82 cases per 100000 and 1.63 cases per 100000 [9]). Fourth, the primary symptoms of achalasia are mostly gastrointestinal, whereas respiratory symptoms are less frequent. In up to $40 \%$ of cases of achalasia, pulmonary disorders such as cough, wheezing, and recurrent aspiration can occur, although DAB is very rare [10]. Bronchiolitis associated with chronic aspiration can considerably hamper diagnosis. DAB should be considered in patients with respiratory symptoms such as chronic cough, wheezing, obstruction, persistent radiologic abnormalities in high-resolution $\mathrm{CT}$, and a high risk of aspiration. Given the scope of the respiratory changes we report, the possible consequences of a further delay in surgical treatment of achalasia could be serious. Our findings confirm the prevailing stance of asthma experts who claim that if asthma symptoms persist despite intensive pharmacological treatment, it is advisable to revisit the patient's clinical history, bearing in mind the possibility of a diagnosis that mimics asthma.

\section{Funding}

The authors declare that no funding was received for the present study.

\section{Conflicts of Interest}

The authors declare that they have no conflicts of interest.

\section{References}

1. Chung KF, Wenzel SE, Brozek JL, Bush A, Castro M, Sterk PJ, et al. International ERS/ATS guidelines on definition, evaluation and treatment of severe asthma. Eur Respir J. 2014;43:343-73.

2. Kim S, Lee $\mathrm{CH}$, Jin $\mathrm{KN}$, Cho SH, Kang HR. Severe asthma phenotypes classified by site of airway involvement and remodeling via chest CT scan. J Investig Allergol Clin Immunol. 2018;28(5):312-20.

3. Robinson DS, Campbell DA, Durham SR, Pfeffer J, Barnes PJ, Chung KF. Systematic assessment of difficult-to-treat asthma. Eur Respir J. 2003;22:478-83.

4. Matsuse T, Oka T, Kida K, Fukuchi Y. Importance of diffuse aspiration bronchiolitis caused by chronic occult aspiration in the elderly. Chest. 1996;110:1289-93.

5. Akritidis N, Gousis C, Dimos G, Paparounas K. Fever, cough, and bilateral lung infiltrates: achalasia associated with aspiration pneumonia. Chest. 2003;123:608-12.

6. Matsuse T, Teramoto S, Matsui H, Ouchi Y, Fukuchi Y. Widespread occurrence of diffuse aspiration bronchiolitis in patients with dysphagia, irrespective of age. Chest. 1998;114(1):350-1. 
7. Teramoto S, Yamamoto H, Yamaguchi $Y$, Tmoita T, Ouchi Y. Diffuse aspiration bronchiolitis due to achalasia. Chest. 2004; 125(1):349-50.

8. Igarashi T, Hirasawa M, Shibuya Y, Natsuizaka T, Asakawa M, Suzuki A. A case of diffuse aspiration bronchiolitis secondary to achalasia of the esophagus [in Japanese]. Nihon Kyobu Shikkan Gakkai Zasshi. 1991;29:1059-63.

9. Sadowski DC, Ackah F, Jiang B, Svenson LW. Achalasia: incidence, prevalence and survival. A population-based study. Neurogastroenterol Motil. 2010;22(9):256-61.

10. Sinan H, Tatum RP, Soares RV, Martin AV, Pellegrini CV, Oelschlager BK. Prevalence of respiratory symptoms in patients with achalasia. Dis Esophagus. 2011;24(2):224-8.

Manuscript received February 8, 2019; accepted for publication May 13, 2019.

Kopeć Agnieszka Department of Internal Medicine and Allergology

Wroclaw Medical University M. Curie-Skłodowskiej 66 50-367 Wroclaw, Poland E-mail: astyrc@wp.pl 